\title{
Evidence for Adenosine Mediation of Atrioventricular Block in the Ischemic Canine Myocardium
}

\author{
Luiz Belardinelli, Elisabete C. Mattos, and Robert M. Berne, Instituto de \\ Cardiologia do RS, Porto Alegre, Brazil; Department of Physiology and \\ Division of Cardiology, University of Virginia Medical Center, \\ Charlottesville, Virginia 22908
}

A B S T RAC T Adenosine levels in oxygen-deprived myocardium can rise to $10-100-\mu \mathrm{M}$ concentrations known to cause atrioventricular (AV) conduction delay and block. We reported that the AV conduction delay and block caused by hypoxia is markedly attenuated by $10 \mu \mathrm{M}$ aminophylline, an adenosine competitive antagonist. The purpose of the present study was to investigate adenosine's role in ischemic AV conduction disturbances. Dogs were anesthetized and instrumented for $\mathrm{His}$ bundle and surface electrogram recordings. The total AV conduction time was subdivided into atrial-His bundle ( $\mathrm{AH})$ and His bundleventricle intervals. The atrioventricular node artery (AVNA) was cannulated for selective injection of drugs in the AV node region. Adenosine (10 to $100 \mu \mathrm{g}$ ), as a 2-ml bolus injection, rapidly produced a dose-dependent, transient increase in the AH interval; a 1,000$\mu \mathrm{g}$ dose caused second degree AV block. The duration of the increase in AH interval was also dose-dependent. Dipyridamole, an inhibitor of nucleoside transport, potentiated the negative dromotropic effects of adenosine, whereas aminophylline attenuated them. In some dogs, after cannulation of the AVNA, first and second degree AV block occurred spontaneously or were induced by rapid atrial pacing. Injection of the aminophylline $(5 \mathrm{mg} / \mathrm{kg}$, i.v.) or theophylline ( 100 $1,000 \mu \mathrm{g}$ ) into the AVNA rapidly reversed the AV blocks. Upon washout of the drugs the AV blocks recurred. We conclude that endogenously released adenosine may account for a major fraction of the AV conduction delay and block associated with impaired blood supply to the AV node, and that theophylline and aminophylline reverse the AV conduction defect by antagonizing the effects of adenosine.

Address reprint requests to Dr. Belardinelli at the University of Virginia Medical Center.

Received for publication 10 November 1980 and in revised form 4 March 1981.

\section{INTRODUCTION}

It has been demonstrated that adenosine and related compounds can produce heart block $(1,2)$. Recently we (3) reported that the atrioventricular $(\mathrm{AV})^{1}$ conduction delay and block caused by adenosine is due solely to a prolongation of the atria-to-His bundle (A-H) interval. Adenosine is also known to depress $\mathrm{Ca}^{2+}$-mediated action potentials in mammalian atria $(4,5)$ as well as inhibit the "slow" $\mathrm{Ca}^{2+}-\mathrm{Na}^{+}$-mediated action potential in the $A-V$ node (6). This suggests that the $\mathrm{A}-\mathrm{V}$ node conduction defect is restricted to the slow channel-dependent tissue of the A-V node.

During hypoxia, the A-V node action potentials are depressed and, concomitantly, the A-H conduction time is markedly increased (7). Furthermore, ischemia and asphyxia also impair A-V node transmission (8-10) and enhance the atrial and ventricular cardiac cell production of adenosine $(11,12)$. In addition, in isolated perfused guinea pig hearts, aminophylline, a competitive antagonist of adenosine, significantly attenuates and reverses the A-V conduction delay and block caused by adenosine and/or hypoxia (3). These findings have led us to hypothesize a causal role for adenosine in the A-V conduction block seen during hypoxia. The objective of this study is to investigate the role of adenosine in the mediation of $\mathrm{A}-\mathrm{V}$ conduction disturbances accompanying myocardial hypoxia and ischemia in an in situ heart preparation.

\section{METHODS}

General. 22 mongrel dogs of either sex weighing 10-18 $\mathrm{kg}$ were anesthetized with sodium pentobarbital $(30 \mathrm{mg} / \mathrm{kg}$, i.v.). Normal saline solution was administered throughout the experiment $(10 \mathrm{ml} / \mathrm{kg}$ per h) via a catheter in the left jugular vein. Arterial blood pressure was continuously re-

${ }^{1}$ Abbreviations used in this paper: A-H, atria-to-Hisbundle; ASA, anterior septal artery; AV, atrioventricular; AVNA, atrioventricular node artery. 
corded on a strip-chart recorder (Gould-Brush 22000, Gould, Inc., Medical Products Div., Oxnard, Calif.) from a catheter positioned in the aorta via the right femoral artery. Under controlled ventilation, a left thoracotomy at the fourth intercostal space was performed, and the heart exposed by pericardiotomy. For selective perfusion of the A-V node region, the technique developed by Nadeau and Amir-Jahed (13) was used. In brief, the atrioventricular node artery (AVNA), a distal branch of the left circumflex, was carefully dissected. Sutures were placed around it, but the vessel was not cannulated until control measurements were made. The AVNA was then cannulated with a small polyethylene catheter and a continuous microdrip of heparinized physiological salt solution was given to keep the catheter patent.

Electrical pacing at rates ranging from 2.2 to $5.5 \mathrm{~Hz}$ was applied to the atrium through Teflon-coated stainless steel wires sutured to the left atrial appendage. Electrical stimulation was delivered from a Grass stimulator (model S44, Grass Instrument Co., Quincy, Mass.) via a stimulus isolation unit as rectangular wave pulses of 2-3 ms.

A His bundle electrogram was obtained with either a standard pacing or tripolar electrode catheter $(5 F)$ having a $1-\mathrm{cm}$ interelectrode distance. The electrode catheter was introduced into the aorta via the left carotid artery and then advanced under manual control into the ascending aorta and finally wedged in the noncoronary cusp of the aortic valve $(14,15)$. Its position was confirmed at the end of each experiment. Extracellular electrograms from atrium and ventricle were obtained with plunge electrodes, i.e., Teflon-coated stainless steel wires ( 0.0045 inch Diam) inserted into the left atrial appendage and left ventricle with use of 25-gauge hypodermic needles (16). A Lead-II electrocardiogram was continuously monitored and recorded at a paper speed of $50 \mathrm{~mm} / \mathrm{s}$. His bundle, atrial and ventricular electrograms were obtained by connecting the electrode terminals to a differential amplifier (Tektronix model 5A22n, Tektronix, Inc., Beaverton, Ore.). The signals were amplified and displayed on a dual-beam oscilloscope (Tektronix model 5440). Both His bundle and left atrial and ventricular electrograms were filtered with a low cutoff of $80 \mathrm{~Hz}$ and a high cutoff of $1 \mathrm{kHz}$. Oscilloscope signals were displayed at sweep speeds of $10-50 \mathrm{~ms} / \mathrm{cm}$ and photographed with a Kymographic camera (Grass model C4).

In all experiments either postmortem coronary angiograms or injections of india ink were performed to verify the anatomy and the area perfused by the cannulated AVNA.

Measurements. On the left atrial, ventricle, and $\mathrm{His}$ bundle electrograms the stimulus artifact (S), the onset of atrial (A) and ventricular $(\mathrm{V})$ depolarization, and the His spike $(\mathrm{H})$ were identified. These features allowed us to measure: $(a)$ Cycle length (C.L.) as the inter-stimulus interval; (b) A-H interval, which represents the atrial-to-His bundle conduction time; (c) H-V interval, which represents the His bundle-toventricular conduction time; and (d) A-V interval, which represents the atrial-to-ventricular conduction time (A-VCT).

In Lead II of the electrocardiogram, the atrial depolarization ( $P$ wave) and ventricular depolarization (QRS) were identified. The intervals $P-R$ and $P-Q$, which represent the conduction time from the atrium to the ventricle, were measured. All the measurements are expressed in milliseconds.

Procedures. Before cannulation of the AVNA, control measurements were taken at different rates of pacing (2.5 to $5.5 \mathrm{~Hz}$ ). After cannulation of the AVNA new measurements were obtained at rates between 2.5 to $4.0 \mathrm{~Hz}$. When the total A-V conduction time in pre- and postcannulation periods differed significantly $(P<0.05)$, the dog was considered to have an $\mathrm{A}-\mathrm{V}$ conduction disturbance. Control measurements preceded and followed all experimental interventions involving injection of adenosine or other drugs into the AVNA.

Adenosine (Sigma Chemical Co., St. Louis, Mo.) was dissolved in physiological salt solution to achieve concentrations of 10,100 , and $1,000 \mu \mathrm{g} / \mathrm{ml}$, and infused into the AVNA as a bolus of 1-2 ml. Each dose of adenosine was injected in duplicate and responses averaged. Dipyridamole, an inhibitor of adenosine uptake, and aminophylline, a competitive antagonist of adenosine, were used to investigate their ability to potentiate and attenuate the effects of adenosine, respectively. In the dogs treated with dipyridamole or aminophylline, each infused dose of adenosine preceded and followed the systemic administration of dipyridamole $(250 \mu \mathrm{g} / \mathrm{kg}$, i.v.) and aminophylline $(5 \mathrm{mg} / \mathrm{kg}$, i.v.). As described above, each dose of adenosine was injected in duplicate and its response was averaged unless otherwise noted. Theophylline and atropine (both from Sigma Chemical Co.) were also prepared in physiological salt solution to achieve the desired concentrations. Theophylline was administered into the AVNA as bolus injections of $1-2 \mathrm{ml}$ at doses of 100 and $1,000 \mu \mathrm{g}$. Between all the interventions the AVNA was continuously perfused with physiological salt solution to assure complete washout of the infused drugs and keep the artery patent.

A subgroup of 10 dogs was pretreated with propranolol $(0.5 \mathrm{mg} / \mathrm{kg}$, i.v.). Propranolol was given before the cannulation of AVNA and thereafter these dogs were submitted to the same procedures as the other dogs. All parameters measured were expressed as mean \pm SEM. The statistical analysis was based on the T-distribution for paired (experimental vs. average pre- and postcontrol) data.

\section{RESULTS}

Effects of adenosine. In 10 of 22 dogs no significant $\mathrm{A}-\mathrm{V}$ conduction disturbance developed during the $3 \mathrm{~h}$ after cannulation of the AVNA even when the hearts were paced at 2.5-3.5 Hz. In this group of dogs, adenosine was infused into the AVNA.

Adenosine injected as a $2-\mathrm{ml}$ bolus $(10-1,000 \mu \mathrm{g})$ into the AVNA caused an immediate but transient prolongation of the A-V conduction time (Fig. 1). In the experiment depicted in Fig. 1, the bolus infusion of physiological salt solution had no significant effect on A-V conduction time. In contrast, the bolus injection of adenosine $(10 \mu \mathrm{g} / \mathrm{ml}$ and $100 \mu \mathrm{g} / \mathrm{ml})$ into the AVNA prolonged the A-H interval without affecting the $\mathrm{H}-\mathrm{V}$ interval (Fig. 1). Thus, the increase in the A-V conduction time is solely due to a lengthening of the A-H interval. Fig. 2 (panel B) illustrates the electrocardiogram from one experiment in which adenosine at $1,000 \mu \mathrm{g} / \mathrm{ml}$ produced a transient second degree A-V block (2:1 A-V block). In 2 of 10 dogs, the first bolus injection of adenosine $(1,000 \mu \mathrm{g} / \mathrm{mg})$ failed to produce second degree A-V block, however, a second bolus injection after repositioning of the catheter in the AVNA resulted in second degree A-V block.

Fig. 3 shows that the prolongation of the $A-H$ interval produced by adenosine is significant and dose dependent. The cannulation of the AVNA in these nine dogs did not significantly increase the A-H interval (Fig. 3). In fact, 10 dogs did not develop any degree 

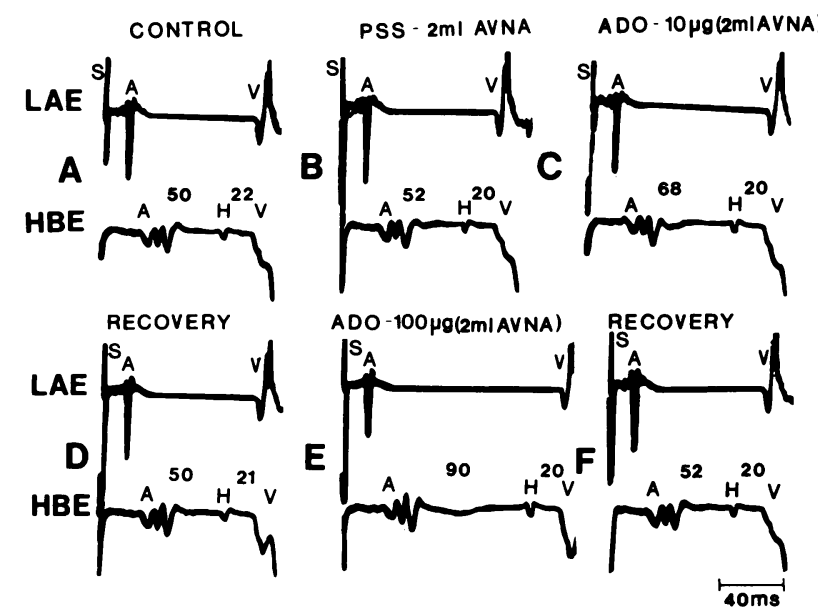

Figure 1 Effect of adenosine (Ado) injected into the AVNA on the $\mathrm{A}-\mathrm{V}$ conduction time. In each panel the upper record is left atrial electrogram (LAE) and the lower record is the His bundle electrogram (HBE). Numbers in the lower traces specify the A-H and $\mathrm{H}-\mathrm{V}$ intervals in milliseconds. A: Control record (postcannulation). B: Bolus injection of $2 \mathrm{ml}$ of physiological salt solution (PSS). Note lack of effect on $\mathrm{A}-\mathrm{H}$ interval. C: infusion of $2 \mathrm{ml}$ containing $10 \mu \mathrm{g}$ adenosine transiently prolonged the A-H interval. D: $5 \mathrm{~min}$ after infusion of adenosine in $\mathrm{C}$, the $\mathrm{A}-\mathrm{H}$ interval recovered to the control level. E: Infusion of adenosine $100 \mu \mathrm{g}$ prolonged A-H; note large effect relative to $\mathbf{C}$. F: $5 \mathrm{~min}$ after the bolus injection in E. Heart paced at $2.5 \mathrm{~Hz}$ (cycle length $400 \mathrm{~ms}$ ) throughout. Time calibration in $\mathbf{F}$ applies to all traces.

of A-V block after AVNA cannulation. However, one dog was not included in this group (Fig. 3) since only two doses $(100-1,000 \mu \mathrm{g})$ of adenosine were tested. The duration of the increase in $\mathrm{A}-\mathrm{V}$ conduction time caused by adenosine was also dose dependent (Table I). Systemic infusion of similar doses of adenosine

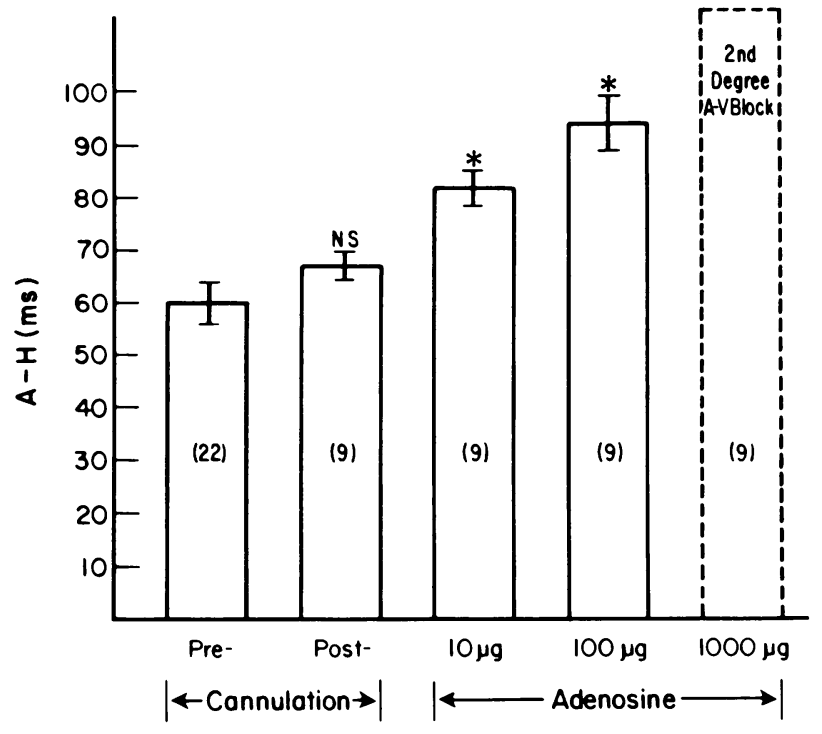

FIGURE 3 Summary of the data demonstrating the dosedependency of adenosine effects on the A-H interval. In the nine dogs tested, there was no significant (NS) difference in the A-H interval in the postcannulation (AVNA) period relative to the precannulation period (compare first two bars). Adenosine, at 1,000 $\mu \mathrm{g}$, produced second degree A-V block. Values expressed as mean $\pm S E M$. Number in parentheses refer to the number of dogs. ${ }^{*} P<0.05$ relative to control (postcannulation).

had no effect on A-V conduction time. The bolus injection of adenosine and physiological salt solution into the AVNA did not cause change in arterial blood pressure except when A-V block occurred.

Effects of dipyridamole on adenosine-induced changes in conduction. 7 of the 10 dogs that did not develop A-V block after cannulation of the AVNA were ad-
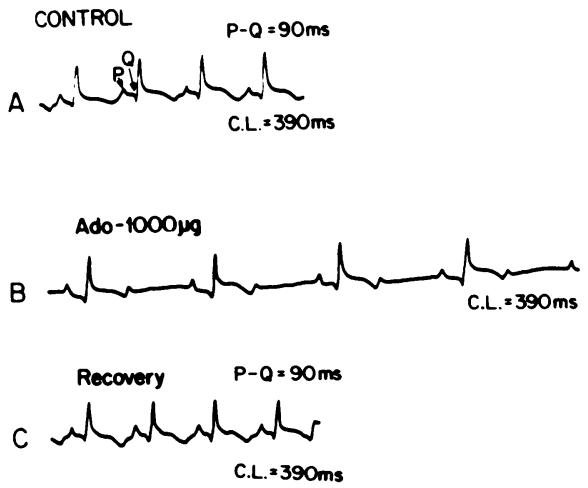
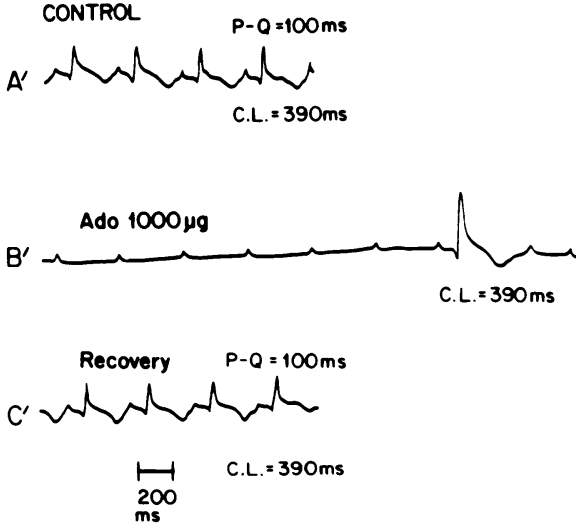

FIGURE 2 Potentiation of the effects of adenosine (Ado) on A-V conduction time by dipyridamole. A: Control (no injection). B: Injection of $2 \mathrm{ml}$ of Ado $(1,000 \mu \mathrm{g})$ into the AVNA. C: Trace obtained $10 \mathrm{~min}$ after the injection of Ado in B. In panels $A^{\prime}-C^{\prime}$ dypyridamole (250 $\mu \mathrm{g} / \mathrm{kg}$; i.v.) was present. $B^{\prime}$ : Note marked potentiation of the effect of $1,000 \mu \mathrm{g}$ injection of Ado by dipyridamole. $\mathrm{C}^{\prime}$ : Return of P-Q interval to control. Heart paced at $2.6 \mathrm{~Hz}$ throughout. Time calibration in $\mathrm{C}^{\prime}$ applies to all traces. 
TABLE I

Duration of A-V Conduction Delay

\begin{tabular}{lccr}
\hline \multicolumn{1}{c}{ Adenosine dose } & 10 & 100 & \multicolumn{1}{c}{1,000} \\
\hline & & $\mu g$ & \\
Adenosine alone & $1.10 \pm 0.20 \mathrm{~min}$ & $2.00 \pm 0.33 \mathrm{~min} *$ & $4.45 \pm 0.63 \mathrm{~min} *$ \\
Dipyridamole + adenosine & $5.40 \pm 0.85 \mathrm{~min} \ddagger$ & $7.50 \pm 0.95 \mathrm{~min} \ddagger$ & $10.12 \pm 1.27 \mathrm{~min} \ddagger$ \\
\hline
\end{tabular}

* $P<0.05$ comparing different doses of adenosine.

$\$ P<0.05$ comparing adenosine alone to dipyridamole + adenosine.

ministered dipyridamole $(250 \mu \mathrm{g} / \mathrm{kg}$, i.v.). In three of the seven dogs treated with dipyridamole, first and/or second degree A-V block appeared within 3 to $5 \mathrm{~min}$ after its administration. In the remaining four dogs that did not develop A-V block, adenosine was reinjected into the AVNA. As illustrated in Figs. 2 and 4 and Table I, dipyridamole potentiated the effects of adenosine both in magnitude and duration. In four dogs dipyridamole alone did not prolong the $\mathrm{A}-\mathrm{H}$ interval (Fig. 4). However, the prolongation of the $\mathrm{A}-\mathrm{H}$ and $\mathrm{P}-\mathrm{Q}$ interval caused by adenosine was significantly increased in the presence of dipyridamole (Figs. 2, $\mathrm{B}^{\prime}$ and 4). Fig. 2 shows that when adenosine $(1,000$ $\mu \mathrm{g} / \mathrm{ml}$ ) is injected into the AVNA after pretreatment with dipyridamole, the second degree A-V block is converted to complete A-V block (compare panel B to $\left.B^{\prime}\right)$. As already pointed out, the effects of adenosine were transient. However, in the dogs pretreated with dipyridamole, the duration of $\mathrm{A}-\mathrm{V}$ conduction delay and block caused by adenosine were significantly increased (Table I). The example illustrated in Fig. 2 shows a marked sensitization to adenosine by dipyridamole. The data from which the bar graph (Fig. 4)

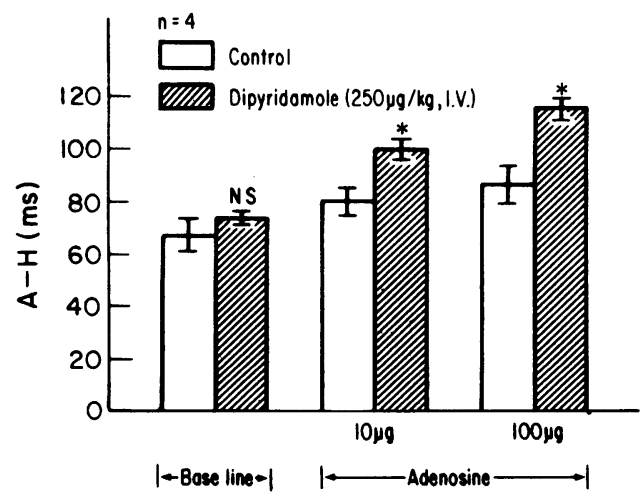

FIGURE 4 Summary of the data demonstrating the potentiation of the effects of adenosine injected into the AVNA by dipyridamole. Significant effect $(P<0.05)$ relative to the control $(0,10$, and $100 \mu \mathrm{g}$ adenosine alone) indicated by $*$. The four bars on the right side are the effects of adenosine alone and the effects of adenosine plus dipyridamole. Dipyridamole was infused intravenously. Note that dipyridamole alone caused no significant (NS) prolongation of A-H interval in this group of dogs. was constructed do not include experiments in which second degree A-V block occurred. Second degree A-V block was observed in two animals (one trial each) with a $100-\mu \mathrm{g}$ dose and only once with a $10-\mu \mathrm{g}$ dose in the presence of dipyridamole.

Effects of aminophylline on adenosine-induced changes in conduction. Fig. 5 shows that intravenous administration of $5 \mathrm{mg} / \mathrm{kg}$ of aminophylline significantly attenuated the prolongation of the A-H interval caused by $10-$ and $100-\mu \mathrm{g}$ bolus injections of adenosine into the AVNA. Furthermore, two animals (1 trial each) treated with aminophylline showed immediate reversion of the long-lasting complete A-V block caused by adenosine $(1,000 \mu \mathrm{g})$ injection in dogs pretreated with dipyridamole (not shown). In addition, pretreatment with aminophylline completely prevented or markedly reduced the duration of the A-V conduction delays or blocks induced by adenosine (not shown). Aminophylline (100-1,000 $\mu \mathrm{g}$ ) and theophylline $(100-1,000 \mu \mathrm{g})$ injected into the AVNA (four dogs, six trials) also prevented and/or reversed the adenosine-induced A-H prolongation. In contrast, atropine $(20 \mu \mathrm{g})$ injected into the AVNA (three dogs, six trials) failed to antagonize the effects of adenosine. Also, aminophylline $(2.5 \mathrm{mg} / \mathrm{kg}$, i.v. $)$ per se did not

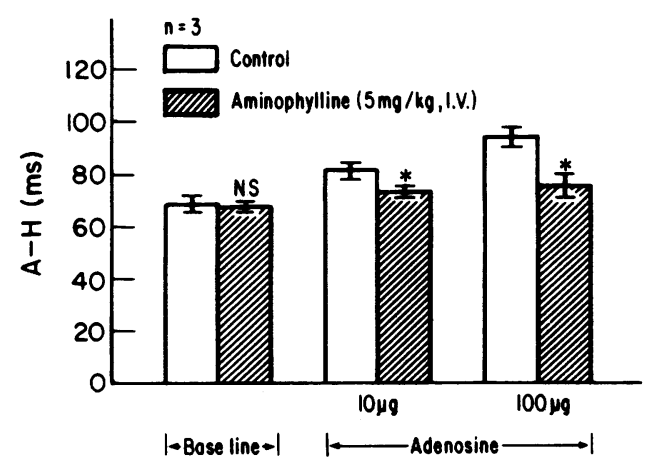

Figure 5 Summary of the data demonstrating the attenuation of adenosine effects on $\mathrm{A}-\mathrm{V}$ conduction by aminophylline. ${ }^{*}$, statistically significant $(P<0.05)$ reduction in the A-H prolongation in the presence of adenosine plus aminophylline compared to the control (10 or $100 \mu \mathrm{g}$ adenosine alone). 


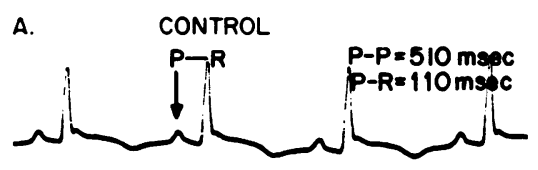

$H R=118 \mathrm{bpm}$

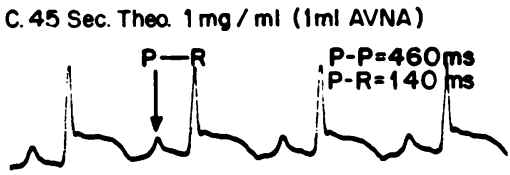

$H R=130 \mathrm{bpm}$

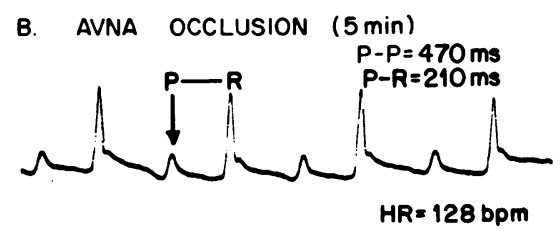

D. I min. Theo Washout

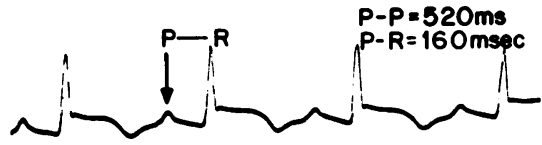

$H R=115 \mathrm{bpm}$

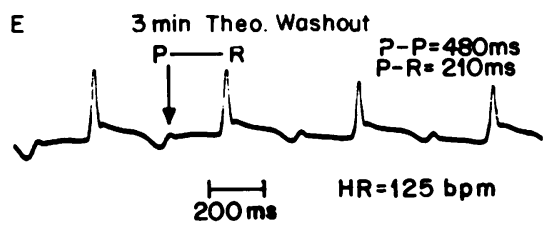

Figure 6 Theophylline (Theo) reversal of first degree A-V block caused by AVNA cannulation. A: control record (precannulation). B: 5 min after the AVNA cannulation; note prolongation of P-R interval. C: $45 \mathrm{~s}$ following bolus injection of theophylline into the AVNA; note marked reduction in the P-R interval. D-E: One (D) and three (E) min after washout of theophylline. Heart was not paced.

cause any significant changes in the $\mathrm{A}-\mathrm{V}$ conduction time.

Reversal of the ischemic A-V block by theophylline and aminophylline. In 22 dogs (paced at $2.5 \mathrm{~Hz}$ ) before cannulation of the AVNA the A-V conduction time averaged $84 \pm 3 \mathrm{~ms}$, the $\mathrm{A}-\mathrm{H}$ and $\mathrm{H}-\mathrm{V}$ intervals were $60 \pm 4$ and $24 \pm 2 \mathrm{~ms}$, respectively. Increasing the rate of pacing produced a progressive prolongation of the A-H interval, and second degree A-V block (Wenckebach type) occurred at an average pacing rate of $4.6 \pm 0.1 \mathrm{~Hz}$. Mean arterial blood pressure was $94 \pm 4 \mathrm{~mm} \mathrm{Hg}$ and remained constant throughout the experiment.

12 of the 22 dogs developed A-V conduction disturbances after cannulation of the AVNA. In 5 of the 12 dogs first degree A-V block occurred spontaneously (i.e., without pacing); one example is shown in Fig. 6. In seven other dogs second degree A-V block (Wenckebach type) was induced by pacing the hearts at rates ranging from 2.7 to $3.5 \mathrm{~Hz}$ (Fig. 1). After $20-30 \mathrm{~min}$ of atrial pacing, two of seven dogs developed second degree A-V block and one complete heart block at their spontaneous heart rates. Thus, in 5 of the 22 dogs (23\%) first degree A-V block occurred spontaneously and in seven other dogs the A-V block was induced by rapid pacing. In these 12 dogs the efficacy of theophylline (directly infused into the AVNA) and/or aminophylline (intravenous administration) in reversing the A-V block were tested.

Theophylline. In 21 trials (eight dogs), theophyl- line $(100-1,000 \mu \mathrm{g})$ was injected as a 1-2-ml bolus into the AVNA. In six of these dogs, theophylline rapidly reversed the A-V block (Fig. 6) and washout of theophylline resulted in recurrence of the A-V block. In one dog with second degree A-V block, theophylline failed to restore $1: 1 \mathrm{~A}-\mathrm{V}$ condution. In all three dogs that developed A-V block after pretreatment with dipyridamole, theophylline successfully restored normal A-V conduction (not shown). In contrast, atropine $(20 \mu \mathrm{g})$ injected into the AVNA failed to restore normal A-V conduction in four trials in two dogs. In one dog ventricular fibrillation developed immediately after the third bolus injection of theophylline.

Aminophylline. Aminophylline $(2.5-5 \mathrm{mg} / \mathrm{kg}$ ) was administered intravenously in eight dogs. In all but two dogs, normal A-V conduction was restored upon intravenous administration of aminophylline. For example, in one experiment (not illustrated) the A-H interval increased to $97 \mathrm{~ms}$ after $20 \mathrm{~min}$ of AVNA cannulation. 2 min after a bolus intravenous infusion of aminophylline $(5 \mathrm{mg} / \mathrm{kg}$ ) the $\mathrm{A}-\mathrm{H}$ interval decreased to $87 \mathrm{~ms}$ and at $4 \mathrm{~min}$ the $\mathrm{A}-\mathrm{H}$ was reduced to $56 \mathrm{~ms}$. In two of the dogs that were followed for $>2 \mathrm{~h}$ after the first infusion of aminophylline, the A-H interval was progressively prolonged, i.e., the A-V block recurred. A second bolus injection of aminophylline in these two dogs restored normal A-V conduction. Aminophylline $(5 \mathrm{mg} / \mathrm{kg}$, i.v.) was also efficacious in reversing the second degree Wenckebach type $\mathrm{A}-\mathrm{V}$ block (Fig. 7). In the experiment illustrated in Fig. 7 


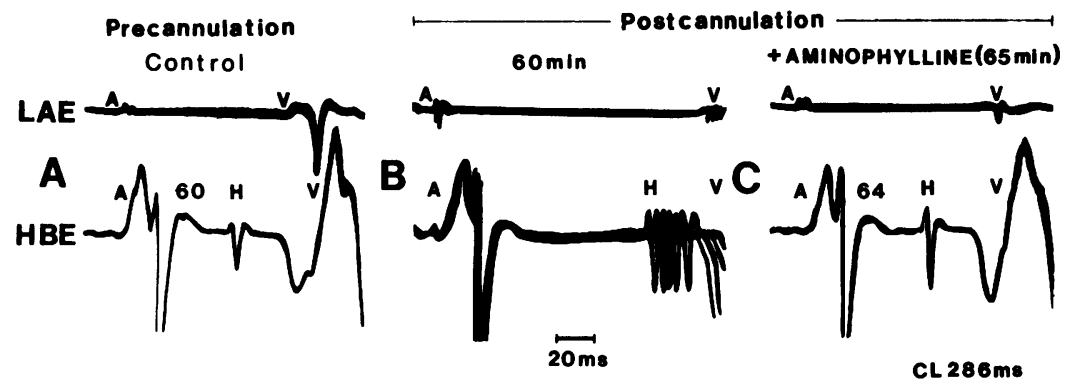

Figure 7 Aminophylline reversal of second degree A-V block (Wenckebach type) caused by AVNA cannulation plus atrial pacing. In each panel upper record is left atrial electrogram (LAE) and the lower record is the His bundle electrogram (HBE).Number in the lower traces denote the A-H interval in milliseconds. A: Control record (precannulation). B: 60 min after AVNA cannulation. Several superimposed sweeps in which the A-H interval progressively lengthened (Wenckebach phenomenon). C: $5 \mathrm{~min}$ after bolus intravenous administration of aminophylline $(5 \mathrm{mg} / \mathrm{kg})$; note restoration of normal A-V conduction. Heart paced at 3.5 $\mathrm{Hz}$ throughout. Stimulus artifact removed from traces.

the Wenckebach type A-V block could be induced by rapid atrial pacing $(3.5 \mathrm{~Hz})$ after $60 \mathrm{~min}$ of AVNA cannulation. A bolus intravenous injection of aminophylline rapidly arrested the Wenckebach periodicity, and within $5 \mathrm{~min}$ the $\mathrm{A}-\mathrm{H}$ interval was near the control level (Fig. 7, panel C). Similar results were obtained in four other dogs.

Effects of adenosine on ischemia-induced A-V block. In three of the dogs that developed conduction disturbances following cannulation of the AVNA, the ability of adenosine to further impair $\mathrm{A}-\mathrm{V}$ conduction was tested. As shown in Fig. 8, adenosine (100 $\mu \mathrm{g})$ injected into the AVNA caused a transient but complete heart block. In all three dogs tested, adenosine produced complete heart block. Thus, a preexistent A-V conduction disturbance (due to AVNA cannulation) is exacerbated by adenosine.

Propranolol-treated dogs. Methylxanthines are known to release catecholamines (17). Hence, propranolol was used to test the possibility that the reversal of adenosine and ischemia-induced A-H prolongation by theophylline and aminophylline was due to catecholamine release.

10 dogs received propranolol $(0.5 \mathrm{mg} / \mathrm{kg})$ intravenously before cannulation of the AVNA. The control (before propranolol) A- $\mathrm{H}$ and $\mathrm{H}-\mathrm{V}$ intervals were $57 \pm 4$ $\mathrm{ms}$ and $24 \pm 2 \mathrm{~ms}$, respectively. 5-10 min after propranolol administration, the $\mathrm{A}-\mathrm{H}$ was prolonged to $75 \pm 6$ $\mathrm{ms}$ and the $\mathrm{H}-\mathrm{V}$ interval remained more or less unchanged $(21 \pm 4 \mathrm{~ms})$. The prolongation of the $\mathrm{A}-\mathrm{H}$ interval caused by adenosine was not affected by pretreatment with propranolol. In addition, the efficacy of theophylline and aminophylline in reversing the adenosine- and ischemia-induced A-H prolongation was the same as in the dogs that were not pretreated with propranolol.

\section{DISCUSSION}

Ligation of the AVNA for direct perfusion of the A-V node area in in situ and/or isolated dog hearts has been performed by several investigators $(13,18-20)$. The blood supply to the AV node of the dog originates from two sources, the AVNA, and the anterior septal artery (ASA) $(21,22)$. The proximal portion of the A-V node is mainly supplied by the AVNA whereas the distal part of the node, the A-V bundle and proximal bundle branches are supplied by branches of the ASA. There are numerous anastomoses between the AVNA and the ASA $(21,22)$. Thus, the dual arterial supply to the A-V node and the accompanying anastomoses may assure sufficient blood supply to the A-V node even when the AVNA is occluded. According to James (18), one-third of the dogs studied developed prolongation of the P-R interval after $1 \mathrm{~h}$ of AVNA cannulation. In our experiments, $23 \%$ of the dogs developed significant prolongation of the A-H interval (without atrial pacing) within the lst $h$ after cannulation of the AVNA. However, after cannulation of the AVNA second degree $\mathrm{A}-\mathrm{V}$ block could be induced by rapid atrial pacing ( 3.0 to $3.5 \mathrm{~Hz}$ ) in seven dogs. This finding suggests that after ligation of the AVNA, blood supply is compromised despite the presence of collateral circulation, since an increase in oxygen demand by rapid pacing led to an impairment in $\mathrm{A}-\mathrm{V}$ node transmission. Thus, it appears that in a subset of dogs the impairment of the blood supply to the A-V node, that was not apparent at low heart rates, was unmasked by rapid atrial pacing.

It is well known that cardiac cells can produce increased quantities of adenosine whenever an imbalance between oxygen supply and demand is established (23). A significant correlation between myo- 

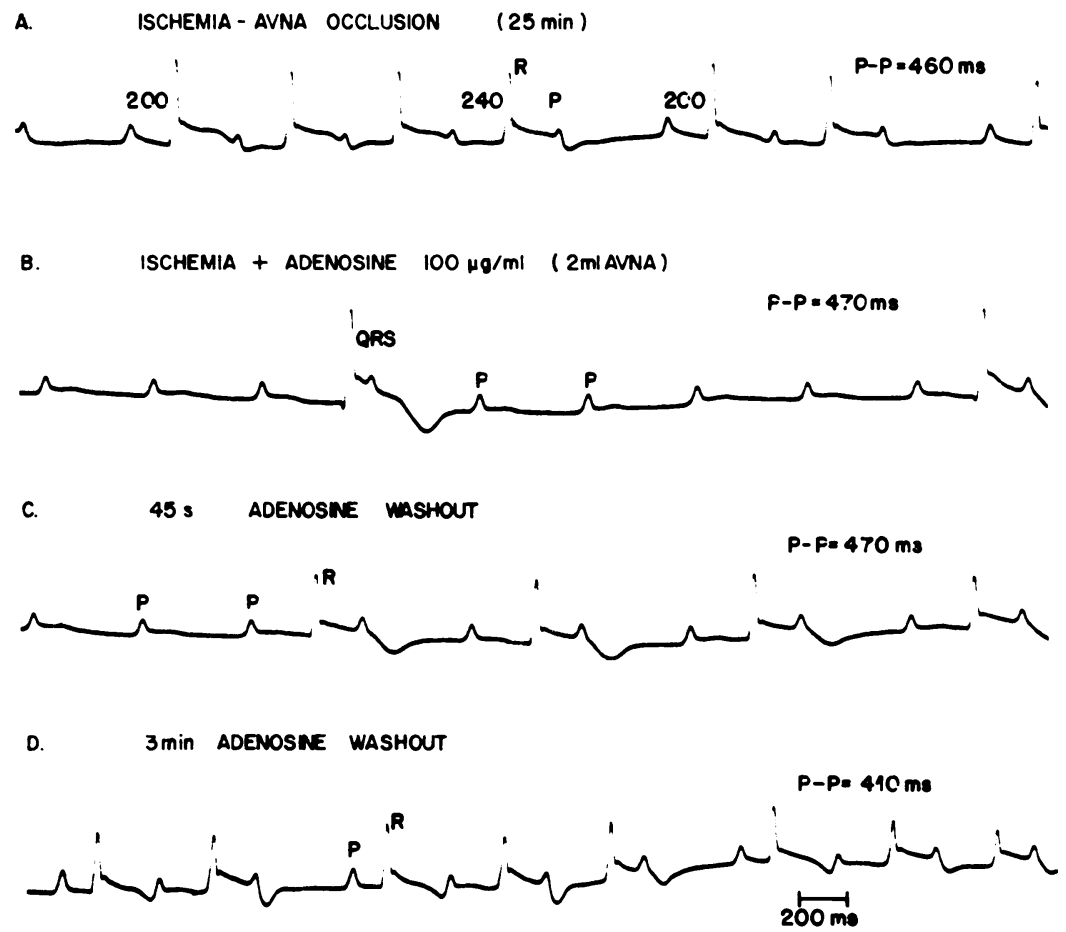

FIGURE 8 Exacerbation of the ischemia-induced A-V block by adenosine injection into the AVNA. A: Trace obtained 25 min after cannulation of the AVNA. Numbers denote the P-R interval in milliseconds. Note the A-V block. B-D: $20 \mathrm{~s}$ (B), $45 \mathrm{~s}$ (C) and $3 \mathrm{~min}$ (D) after injection of Ado. Time calibration in D applies to all traces. Heart was not paced.

cardial oxygen consumption and adenosine production have been recently demonstrated (24). It is even more likely to have greater production of adenosine by cardiac cells under conditions of increased myocardial oxygen demand when blood flow and oxygen availability are limited. Consistent with this concept is the observation that angina pectoris induced by rapid atrial pacing in patients with coronary artery disease is accompanied by release of adenosine into the coronary sinus blood (25). This situation is somewhat similar to the one observed in the seven dogs in which rapid atrial pacing after impairment of the blood supply to the A-V node (by AVNA cannulation) induced second degree $\mathrm{A}-\mathrm{V}$ block. The reversal of first degree and second degree A-V block by either direct infusion of theophylline into the AVNA or intravenous administration of aminophylline suggest that adenosine is involved in the genesis of this type of A-V block.

Adenosine levels in dog heart after $15 \mathrm{~s}$ of coronary occlusion is $\sim 2 \mathrm{nmol} / \mathrm{g}$ of left ventricle, corresponding to $\sim 10 \mu \mathrm{M}$ adenosine concentration in the extracellular space (26). From values reported in isolated guinea pig hearts after 5 min of hypoxic perfusion, it would be anticipated that interstitial adenosine concentrations could be $\sim 0.1 \mathrm{mM}$ to $10 \mu \mathrm{M}(11,12)$.
Adenosine at $10 \mu \mathrm{M}$ could account for the A-V conduction delay and block observed at $5 \mathrm{~min}$ of hypoxic perfusion in isolated guinea pig hearts (3). Unfortunately, in the present experimental model, we cannot determine what myocardial levels of adenosine are reached by 2 -ml bolus injections of 10,100 , and 1,000 $\mu \mathrm{g}$ adenosine into the AVNA.

We $(3,27,28)$ have recently proposed adenosine as a possible candidate for the biochemical mediation of the A-V node conduction delay and block observed in hypoxic isolated guinea pig hearts. The present data obtained from in situ canine hearts provide evidence in support of that proposal, which is now extended to include ischemia. The present findings are consistent with previous reports $(1,2,29,30)$ that adenosine increases atrioventricular conduction time, and that this effect is due to an increase in the conduction delay between the atria and His bundle $(3,28)$. Adenosine is known to depress the catecholamine-induced $\mathrm{Ca}^{2+}$ dependent action potentials in mammalian atria, whereas the fast-channel action potentials are not affected $(4,5)$. Since the electrical activity of the nodal cells ( $\mathrm{N}$-zone) of the A-V node is mainly dependent on "slow" $\mathrm{Ca}^{2+}-\mathrm{Na}^{+}$-mediated action potentials (31), it is reasonable to assume that the N-zone of the A-V 
node is likely to be vulnerable to adenosine. Preliminary studies (6) on isolated A-V node preparations have indicated that adenosine depresses the action potentials of nodal cells. A possible action of adenosine in the atrionodal cells (AN-zone) remains to be investigated. The adenosine-induced $\mathrm{A}-\mathrm{H}$ prolongation is consistent with the fact that the proximal portion of the $\mathrm{A}-\mathrm{V}$ junctional region is more sensitive to drugs that interfere with slow $\mathrm{Ca}^{2+}{ }_{-} \mathrm{Na}^{+}$inward current than the distal portion (32-34).

The observed selective prolongation of the A-H interval caused by injection of adenosine into the AVNA is similar to that observed in the same type of preparation with various slow-channel blockers, such as verapamil, D-600, manganese chloride, and lanthanum $(20)$, as well as with acetylcholine $(35,18)$. However, in comparison to the effects of the slow-channel blockers, the effects of adenosine have a rapid onset (seconds) and are rapidly and completely reversed upon washout of the nucleoside. Acetylcholine-induced A-V block is similar to that of adenosine since it is also rapid in onset and is transient $(15,18)$. However, atropine antagonizes the effects of acetylcholine $(15,18)$, whereas the negative dromotropic action of adenosine is not affected by atropine (3).

James et al. (35) suggested that ATP released by ischemic cells could be a candidate for the metabolic mediation of the early ischemic A-V block since ATP $(1-10 \mathrm{mg} / \mathrm{ml})$ infused into the AVNA or the ASA produces complete A-V block. This finding is consistent with the report of Gillespie (36) that ATP, adenylic acid and inosinic acid produce heart block in mammalian hearts. Furthermore, it has also been shown that injection of adenosine into the femoral vein of dogs produces a prolongation of the P-R interval as well as sinus bradycardia (1). It is of interest that these authors (1) reported that in the dog the impairment of A-V conduction caused by adenosine could not be readily evaluated because the accompanying bradycardia affords the A-V node a long recovery period. When the hearts were paced at a constant rate, various degrees of A-V block were consistently obtained with adenosine infusions (1). It has been suggested that the A-V node in the dog is more sensitive to ATP than to adenosine (30). In addition, it appears that there are some species variability concerning the responsiveness of $\mathrm{S}-\mathrm{A}$ and $\mathrm{A}-\mathrm{V}$ node to adenosine ( 1 , 3,30 ), but further investigation is required for the elucidation of these apparent differences. However, the impairment of the A-V node conduction by adenosine and adenine compounds is a reproducible observation.

Any proposed candidate for the biochemical mediation of the A-V conduction delay or block associated with hypoxia or ischemia should meet the fol- lowing criteria: $(a)$ the substance should be produced during hypoxia and ischemia, and attain a concentration sufficient to account for its effects; $(b)$ the substance should increase in concentration at the site of action with a sufficiently fast time-course to account for the effects of hypoxia and ischemia; $(c)$ the substance should mimic the effects of hypoxia and ischemia; $(d)$ agents known to attenuate or potentiate the action of the substance should, respectively reduce or enhance the effect of hypoxia and ischemia. We (3) have previously presented evidence showing that in isolated guinea pig hearts adenosine appears to fulfill at least the last two criteria, whereas the evidence for the first two is indirect and, hence, more speculative. In brief, it was demonstrated (3) that adenosine mimics the effects of hypoxia, and that aminophylline (10 $\mu \mathrm{M}$ ), a competitive antagonist of adenosine (37-39), attenuates and reverses the A-V node conduction delay and block caused by either adenosine or hypoxia. With respect to the fourth criterion, the present study demonstrates that dipyridamole, a blocker of the nucleoside transport $(40,41)$, markedly potentiates (in magnitude and duration) the effects of adenosine and of ischemia (see below) in the A-V node.

The A-V block induced by dipyridamole could be explained by at least three possible mechanisms. First, as shown in this study, dipyridamole potentiates the negative dromotropic effects of adenosine in the A-V node. Second, dipyridamole is known to preferentially dilate small arteriolar resistance vessels, reduce or not affect collateral flow and precipitate a "coronary steal" $(42,23)$, thereby, enhancing the production of adenosine by the myocardial cells. Third, dipyridamole has been shown to increase the level of tissue adenosine in normoxic as well as hypoxic hearts (43, 44). The reversal of the dipyridamole-induced A-V block by theophylline or aminophylline is consistent with the adenosine hypothesis for the mediation of the A-V block.

Methylxanthines, such as theophylline may exert their effects by any of the following mechanisms: (a) translocation of intracellular calcium; (b) inhibition of phosphodiesterase leading to an increase in cyclic AMP; $(c)$ by release of catecholamines; and $(d)$ by blockade of adenosine receptors. The first two mechanism are operative only at high concentration of theophylline. The concentration of theophylline required for phosphodiesterase inhibition is $\sim 0.5 \mathrm{mM}$ to $10 \mathrm{mM}$ (45). Theophylline at concentration of 50 $\mu \mathrm{M}$ would cause an inhibition of phosphodiesterase of only $10 \%$ (46). According to Ogilvie et al. (47), we would predict that the doses of aminophylline used in this study would yield a plasma concentration no higher than $10 \mu \mathrm{g} / \mathrm{ml}$ which would have a minor phosphodiesterase inhibitor effect. Moreover, theo- 
phylline analogs do not antagonize the effects of adenosine $(48,49)$. Since the efficacy of methylxanthines in reversing the adenosine- and ischemia-induced A-H prolongation was not affected by propranolol, the catecholamines released by methylxanthines cannot account for our results. Thus, the most likely mechanism whereby theophylline reversed the effects of adenosine, hypoxia, and ischemia was via its antiadenosine action.

In our preparations it seems that the increased vagal activity, which has been postulated by others $(50,51)$ to mediate the A-V block and the bradycardia observed in posterior myocardial infarction, played very little or no role in the A-V node conduction delay and block. One possible explanation is that the pentobarbital anesthesia, that is known to have a parasympatholytic action (52), would tend to nullify any increase in parasympathetic tone. Thus, our experiments do not rule out an enhanced vagal activity in the A-V node conduction block associated with ischemia. However, the results presented here do strongly support the role of adenosine as a biochemical mediator of the ischemic A-V block. The antiadenosine action of theophylline proved to be an efficacious therapeutic tool in reversing this conduction disturbance. Thus, endogenously released adenosine by ischemic cells appears to play an important role in the $\mathrm{A}-\mathrm{V}$ node conduction delay and block associated with impaired blood supply to the canine A-V node.

Clinical implications. Bradycardia, hypotension and A-V block are frequently observed in acute inferior myocardial infarction (50). According to studies of Adgey et al. (50), $16 \%$ of patients with posterior wall myocardial infarction seen within the 1 st h of onset of symptoms developed bradycardia or A-V block. The reversal of these bradyarrhythmias by atropine have led investigators to attribute them to an augmented vagal discharge. However, the efficacy of atropine in reversing the A-V block appears to be influenced by the time after the onset of symptoms at which the drug is administered (50). The response to atropine in patients seen more than $8 \mathrm{~h}$ after the onset of symptoms of myocardial infarction is very poor (50). Hence, this finding suggests that vagal hyperactivity may play an important role in the early phases of A-V block accompanying inferior myocardial infarction. However, after several hours, a different mechanism may be operative. Local release of negative dromotropic substances and temporary hypoxia have also been considered to play a role $(51,53)$. It is quite conceivable that the mechanism underlying the bradyarrhythmias and A-V block associated with inferior myocardial infarction consists of two mechanisms. It is postulated that in the early phase an increase in vagal activity is responsible for the observed arrhyth- mias, whereas in the later phase a negative dromotropic metabolite released by the ischemic cells may be the major cause of the A-V block.

We have demonstrated that adenosine fulfills some of the important criteria that any candidate must meet to be postulated as a mediator of the ischemic A-V block. It is concluded that endogenously released adenosine by the ischemic cardiac cells may be the negative dromotropic substance underlying the A-V node conduction delay and block accompanying inferior myocardial infarction. Any agent with antiadenosine properties (e.g. theophylline or adenosine deaminase) may prove to be a useful tool in the treatment of such conduction disturbances in a clinical situation.

\section{ACKNOWLEDGMENTS}

Our special thanks to Dr. Fernando A. Lucchese for the use of his laboratory where some of this work was carried out. We would also like to thank Dr. Richard Crampton for his helpful suggestions and Ann Smith and Betty Snoddy for their help in preparing this manuscript.

This research was supported by FINEP-960/78, CNPq222.0181/78 and CAPES $7266 / 78$ from Brazil and by U.S. Public Health Service grant HL 10384.

\section{REFERENCES}

1. Drury, A. N., and A. Szent-Gyorgy. 1929. The physiological activity of adenine compounds with special reference to their action upon the mammalian heart. J. Physiol. (Lond.). 68: 213-217.

2. Stafford, A. 1966. Potentiation of adenosine and the adenine nucleotides by dipyridamole. Br.J. Pharmacol. Chemother. 28: 218-227.

3. Belardinelli, L., F. L. Belloni, R. Rubio, and R. M. Berne. 1980. Atrioventricular conduction disturbances during hypoxia. Possible role of adenosine in rabbit and guinea pig heart. Circ. Res. 47: 684-691.

4. Schrader, J., R. Rubio, and R. M. Berne. 1975. Inhibition of slow action potentials of guinea-pig atrial muscle by adenosine: a possible effect on $\mathrm{Ca}^{2+}$ influx. J. Mol. Cell. Cardiol. 7: 427-433.

5. Belardinelli, L., R. Rubio, and R. M. Berne. 1979. Blockade of $\mathrm{Ca}^{2+}$ dependent rat atrial slow action potentials by adenosine and lanthanum. Pfuegers Arch. Eur. J. Physiol. 380: 19-27.

6. Rubio, R., L. Belardinelli, C. I. Thompson, and R. M. Berne. 1979. Cardiac adenosine: electrophysiological effects, possible significance in cell function, and mechanisms controlling its release. In Physiological and Regulatory Functions of Adenosine and Adenine Nucleotides. Edited by H. P. Baer, and G. I. Drummond. Raven Press, New York. 167-182.

7. Senges, J., T. Mizutani, D. Pelzer, J. Brachmann, U. Sonnhof, and W. Kübler. 1979. Effect of hypoxia on the sinoatrial node, atrium and atrioventricular node in the rabbit heart. Circ. Res. 44: 856-863.

8. Bagdonas, A. A., J. H. Stuckey, J. Plera, N. S. Amer, and B. F. Hoffman. 1961. Effects of ischemia and hypoxia on the specialized conducting system of the canine heart. Am. Heart J. 61: 206-218. 
9. Alanis, J., E. Lopez, J. J. Mandoki, and G. Pilar. 1959. Propagation of impulses through the atrioventricular node. Am. J. Physiol. 196: 1171-1174.

10. Zumino, A. Z. P., I. M. Parisi, and E. R. P. De Ceretti. 1970. Effect of ischemia and low-sodium medium on atrioventricular conduction. Am. J. Physiol. 218: 1489-1494.

11. Thomas, R. A., R. Rubio, and R. M. Berne. 1975. Comparison of the adenine nucleotide metabolism of dog atrial and ventricular myocardium. J. Mol. Cell. Cardiol. 7: $115-123$.

12. Rubio, R., V. T. Wiedmeier, and R. M. Berne. 1974. Relationship between coronary flow and adenosine production and release. J. Mol. Cell Cardiol. 6: 517-566.

13. Nadeau, R. A., and A. K. Amir-Jahed. 1965. Selective perfusion of the AV node of the dog by cannulation of the posterior septal artery. Rev. Can. Biol. 24: 291-297.

14. Scherlag, B. J., J. L. Abelleria, and P. Samet. 1971 Electrode catheter recordings from the $\mathrm{His}$ bundle and left bundle in intact dog. In Research in Physiology. Edited by F. F. Kao, D. Koizum, and M. Vassalle. Aulo Gaggi, Bologna, Italy. 223-238.

15. Urthaler, F., and T. N. James. 1975. A comparison of His bundle electrograms recorded from the aortic root and from a plaque sutured near the His bundle. J. Lab. Clin. Med. 85: 711-722.

16. Scherlag, B. J., and E. J. Berbari. 1975. Techniques for His bundle recordings. In $\mathrm{His}$ Bundle Electrocardiography and Clinical Electrophysiology. Edited by O. S. Narula. F. A. Davis Co., Philadelphia. 51-63.

17. Westfall, D. P., and W. W. Fleming. 1968. Sensitivity changes in the dog heart to norepinephrine, calcium and aminophylline resulting from pretreatment with reserpine. J. Pharmacol. Exp. Ther. 159: 98-106.

18. James, T. N., E. S. Bear, R. J. Frink, K. F. Lang, and J. C. Tomlinson. 1970. Selective stimulation, suppression, or blockade of the atrioventricular node and His bundle. J. Lab. Clin. Med. 76: 240-256.

19. Motomura, S., T. Iijema, N. Taira, and K. Hashimoto. 1975. Effects of neurotransmitters injected into the posterior and anterior septal artery on the automaticity of the atrioventricular junctional area of the dog heart Circ. Res. 37: 146-155.

20. Zipes, D. P., and J. C. Fischer. 1974. Effects of agents which inhibit the slow channel on sinus node automaticity and atrioventricular conduction in the dog. Circ. Res. 34: $184-192$.

21. Lumb, G., R. S. Shacklett, and W. A. Dawkins. 1959. Cardiac conduction tissue and its blood supply in the dog. Am. J. Pathol. 35: 467-487.

22. James, T. N. 1965. Anatomy of the A-V node of the dog. Anat. Rec. 148: 15-27.

23. Berne, R. M., and R. Rubio. 1979. Coronary Circulation. Handb. Physiol. 1: 873-952.

24. Miller, W. L., L. Belardinelli, A. Bacchus, D. Foley, R. Rubio, and R. M. Berne. 1979. Canine myocardial adenosine and lactate production, oxygen consumption and coronary blood flow during stellate ganglia stimulation. Circ. Res. 45: 708-718.

25. Fox, A. C., F. E. Reed, E. Glassman, A. J. Kaltan, and B. B. Silk. 1975. Release of adenosine from human hearts during angina induced by rapid atrial pacing. J. Clin. Invest. 53: 1447-1456.

26. Olsson, R. A. 1970. Changes in content of purine nucleoside in canine myocardium during coronary occlusion. Circ. Res. 26: 301-306.

27. Belardinelli, L., F. L. Belloni, R. Rubio, and R. M. Berne.
1979. Adenosine prolongs A-V conduction time in isolated perfused rabbit heart. Circulation. 60(Suppl. II): 11-87.

28. Berne, R. M., L. Belardinelli, R. L. Belloni, and R. Rubio. 1980. Role of adenosine in A-V nodal conduction disturbances during hypoxia in guinea-pig heart. Proc. Int. U. Physiol. SC. 14: 323.

29. Schrader, J., G. Baumann, and E. Gerlach. 1977. Adenosine as inhibitor of myocardial effects of catecholamines. Pfluegers Arch. Eur. J. Physiol. 372: 29-35.

30. Urthaler, F., and T. N. James. 1972. Effects of adenosine and ATP on AV conduction and on AV functional rhythm. J. Lab. Clin. Med. 79: 96-105.

31. Akiyama, T., and H. Fozzard. 1979. Ca and Na selectivity of the active membrane of rabbit A-V nodal cells. Am.J. Physiol. 236: Cl-C8.

32. Benitez, D., D. Mascher, and J. Alanis. 1973. The electrical activity of the bundle of His. The fast and slow inward currents. Pfluegers Arch. Eur.J.Physiol. 345: 61-72.

33. Wit, A. L., and P. F. Cranefield. 1974. Effect of verapamil on the sinoatrial and atrioventricular nodes of the rabbit and the mechanism by which it arrests reentrant atrioventricular nodal tachycardia. Circ. Res. 35: 413-425.

34. Urthaler, F., and T. N. James. 1979. Experimental studies on the pathogenesis of asystole after verapamil in the dog. Am. J. Cardiol. 44: 651-656.

35. James, T. N., E. S. Bear, R. J. Frink, and F. Urthaler, 1971 Pharmacologic production of atrioventricular block with and without initial bundle branch block. J. Pharmacol. Exp. Ther. 179: 338-346.

36. Gillespie, J. H. 1934. The biological significance of the linkages in adenosine triphosphoric acid. J. Physiol. (Lond.). 80: 345-359.

37. Bünger, R., F. J. Haddy, and E. Gerlach. 1975. Coronary responses to dilating substances and competitive inhibition by theophylline in the isolated perfused guinea-pig heart. Pfluegers Arch. Eur. J. Physiol. 358: 218-224.

38. Rall, T. W. 1979. Regulation of cyclic adenosine monophosphate accumulation in brain tissue: interactions of adenosine with other agonists. In Physiological and Regulatory Functions of Adenosine and Adenine Nucleotides. Edited by H. P. Baer and G. I. Drummond. Raven Press, New York. 217-227.

39. Hartzell, H. C. 1979. Adenosine receptors in frog sinus venosus: slow inhibitory potentials produced by adenine compounds and acetylcholine. J. Physiol. (Lond.). 293: 23-49.

40. Kollassa, N., D. Pfleger, and W. Rummel. 1970. Specificity of adenosine uptake into the heart and inhibition by dipyridamole. Eur. J. Pharmacol. 9: 265-268.

41. Patterson, A. R. P. 1979. Adenosine transport. In Physiological and Regulatory Functions of Adenosine and Adenine Nucleotides. Edited by H. P. Baer and G. I. Drummond. Raven Press, New York. 305-313.

42. Fam, W. M., and M. McGregor. 1968. Effect of nitroglycerin and dipyridamole on regional coronary resistance. Circ. Res. 22: 649-659.

43. Kübler, W., P. G. Spieckermann, and H. J. Bretschneider. 1970. Influence of dipyridamole (Persantin) on myocardial adenosine metabolism. J. Mol. Cell. Cardiol. 1: 23-28.

44. Degenring, F. H., R. R. Curnish, R. Rubio, and R. M. Berne. 1976. Effect of dipyridamole on myocardial adenosine metabolism and coronary flow in hypoxia and reactive hyperemia in the isolated perfused guinea pig heart. J. Mol. Cell. Cardiol. 8: 877-888. 
45. Butcher, R. W., and E. W. Sutherland. 1962. Adenosine $3^{\prime}, 5^{\prime}$-phosphate in biological materials. I-Purification and properties of cyclic $3^{\prime}, 5^{\prime}$-nucleotide phosphodiesterase and use of this enzyme to characterize adenosine 3',5'-phosphate in human urine. J. Biol. Chem. 237: $1244-1250$.

46. Beavo, J. A., N. L. Rogers, O. B. Crofford, J. G. Hardman, E. W. Sutherland, and E. V. Newman. 1970. Effects of xanthine derivatives on lipolysis and on adenosine $3^{\prime}, 5^{\prime}$ monophosphate phosphodiesterase activity. Mol. Pharmacol. 6: 597-603.

47. Ogilvie, R. I., P. G. Fernandez, and F. Winsberg. 1977. Cardiovascular response to increasing theophylline concentrations. Eur. J. Clin. Pharmacol. 12: 409-414.

48. Arrif, A. I., and K. Nakatsu. 1976. Adenosine inhibition of isolated rabbit ileum and antagonism by theophylline. J. Pharmacol. Exp. Ther. 199: 208-215.

49. Olsson, R. A., C. J. David, E. M. Khouri, and R. E.
Patterson. 1976. Evidence for an adenosine receptor on the surface of dog coronary myoctyes. Circ. Res. 39: 93-98.

50. Adgey, A. A. J., J. S. Geddes, H. C. Mulholland, D. A. J. Keegan, and J. F. Pantridge. 1968. Incidence, significance, and management of early bradyarrhythmia complicating acute myocardial infarction. Lancet. II: 10971101.

51. James, T. N. 1968. The coronary circulation and conduction system in acute myocardial infarction. Prog. Cardiovasc. Dis. 10: 410-449.

52. Page, I. H., and J. W. McCubbin. 1965. Autonomic regulation of arterial pressure responses. Arch. Intern. Pharmacodyn. 157: 152-165.

53. Sutton, R., and M. Davies. 1968. The conduction system in acute myocardial infarction complicated by heart block. Circulation. 38: 987-992. 